\title{
Putting the clouds back in aerosol-cloud interactions
}

\author{
A. Gettelman \\ National Center for Atmospheric Research, 1850 Table Mesa Dr., Boulder, CO 80305, USA \\ Correspondence to: A. Gettelman (andrew@ucar.edu)
}

Received: 17 July 2015 - Published in Atmos. Chem. Phys. Discuss.: 3 August 2015

Revised: 23 October 2015 - Accepted: 27 October 2015 - Published: 9 November 2015

\begin{abstract}
Aerosol-cloud interactions (ACI) are the consequence of perturbed aerosols affecting cloud drop and crystal number, with corresponding microphysical and radiative effects. ACI are sensitive to both cloud microphysical processes (the " $\mathrm{C}$ " in $\mathrm{ACI}$ ) and aerosol emissions and processes (the "A" in ACI). This work highlights the importance of cloud microphysical processes, using idealized and global tests of a cloud microphysics scheme used for global climate prediction. Uncertainties in key cloud microphysical processes examined with sensitivity tests cause uncertainties of nearly -30 to $+60 \%$ in $\mathrm{ACI}$, similar to or stronger than uncertainties identified due to natural aerosol emissions $(-30$ to $+30 \%$ ). The different dimensions and sensitivities of ACI to microphysical processes identified in previous work are analyzed in detail, showing that precipitation processes are critical for understanding ACI and that uncertain cloud lifetime effects are nearly one-third of simulated ACI. Buffering of different processes is important, as is the mixed phase and coupling of the microphysics to the condensation and turbulence schemes in the model.
\end{abstract}

\section{Introduction}

Aerosols represent the largest uncertainty in our estimates of current anthropogenic forcing of climate (Boucher et al., 2013), limiting our ability to constrain the sensitivity of the current climate to radiative forcing. Aerosols affect climate through direct effects of absorption or scattering, and indirect effects (Twomey, 1977) by changing the number of cloud drops and resulting complex microphysical interactions. Increased aerosol number concentrations are associated with more cloud condensation nuclei (CCN) (Rosenfeld et al., 2008; Twomey and Squires, 1959), leading to higher cloud drop number concentrations $\left(N_{\mathrm{c}}\right)$. The relationship between aerosols and $\mathrm{CCN}$ is affected by a number of factors (Lohmann and Feichter, 2005), including the aerosol type and meteorological conditions. The result is a different population of cloud droplets, depending on aerosol distribution and meteorology.

But that is only the beginning of aerosol effects on clouds. Cloud microphysics (the interactions of a distribution of cloud drops at the micro-meter scale) determines how much water precipitates, the amount of water remaining in the cloud, and the resulting population of cloud drops. In global modeling experiments, aerosol-cloud interactions (ACI) can be altered by the representation of cloud microphysical processes (the "C" in ACI) while the aerosol processes ("A") remain largely unchanged. Menon et al. (2002), Rotstayn and Liu (2005), Penner et al. (2006), Wang et al. (2012) and Gettelman et al. (2013) all looked at changes to autoconversion, while Posselt and Lohmann (2008) looked at changes to precipitation.

ACI are typically quantified by the change in cloud radiative effect (Ghan et al., 2013). ACI occur most readily with liquid sulfate aerosol $\left(\mathrm{H}_{2} \mathrm{SO}_{4}\right)$ derived from sulfur dioxide $\left(\mathrm{SO}_{2}\right)$ assisting the formation of cloud droplets, thus increasing cloud drop numbers. Higher drop numbers affect cloud albedo (Twomey, 1977), and potentially also affect cloud lifetime and dynamics (Albrecht, 1989; Pincus and Baker, 1994). Cloud lifetime and dynamics effects are highly uncertain (Stevens and Feingold, 2009).

Recent work (Carslaw et al., 2013; Ghan, 2013; Kiehl et al., 2000) found large sensitivities of ACI to uncertainty in natural emissions and thus pre-industrial aerosols: the "A" in ACI. But these studies used fixed assumptions about how 
clouds interact with aerosols, assuming aerosols translated into cloud drop numbers based on fixed cloud dynamics and water content (Carslaw et al., 2013), largely ignoring the "C" in ACI. The cloud microphysical state, defined as the combination of cloud liquid water path and drop number, determines cloud microphysical (precipitation rates) and radiative properties. As a result, perturbations to this state from aerosols (ACI) may depend on the base state; i.e., the response of a cloud to a change in CCN may depend on the unperturbed $\mathrm{CCN}$ and resulting drop number.

In this work we quantify the sensitivity of ACI to cloud microphysics with detailed off-line tests and global sensitivity tests of ACI with a cloud microphysics scheme. First, detailed off-line tests will isolate the different components of ACI in a cloud microphysics scheme; off-line tests will include exploration of lifetime effects and microphysical process rates. Then global simulations will analyze the sensitivity of ACI to many different aspects of cloud microphysics, including sensitivity to (1) activation, (2) precipitation, (3) mixed phase processes, (4) autoconversion treatment, (5) coupling to other parameterizations and (6) background aerosol emissions. These processes have been highlighted in previous studies.

The methodology is described in Sect. 2. Detailed off-line tests are in Sect. 3. Global results and sensitivity tests are in Sect. 4, and conclusions are in Sect. 5.

\section{Methods}

The double-moment (mass and number predicting), bulk cloud microphysics scheme described by Morrison and Gettelman (2008) (hereafter MG1) and Gettelman and Morrison (2015) (hereafter MG2) is used for this study. The scheme handles a variable number of droplets specified from an external activation scheme (Abdul-Razzak and Ghan, 2000). It can also run with a fixed droplet and crystal number. The scheme is implemented both in an off-line idealized kinematic driver (KiD) (Shipway and Hill, 2012), as well as in a general circulation model (GCM) - the Community Earth System Model (CESM) (Gettelman and Morrison, 2015). The susceptibility of an earlier version of the scheme to aerosols has been shown by Gettelman et al. (2013) to be similar to detailed models with explicit bin microphysics that represent more accurately the precipitation process (Jiang et al., 2010).

\subsection{Off-line tests}

To isolate and test the microphysics we use a simple onedimensional off-line driver, the KiD (Shipway and Hill, 2012) with the same microphysical parameterization as used in the global model. We use a $1 \mathrm{~s}$ time step, $25 \mathrm{~m}$ vertical resolution and a $3 \mathrm{~km}$ vertical domain in KiD. In the off-line implementation, specified drop numbers are assumed. Here we focus only on warm rain cases. We use several different cases for analysis. The basic case (warm 2 or W2) features multiple $2 \mathrm{~ms}^{-1}$ updrafts over $2 \mathrm{~h}$ (Gettelman and Morrison, 2015; Shipway and Hill, 2012). We have examined three other cases as well, with notation following Gettelman and Morrison (2015). These cases represent some basic idealized clouds commonly used to evaluate cloud microphysical processes such as condensation, precipitation and evaporation. Case 1 (W1) is a single $2 \mathrm{~ms}^{-1}$ updraft that decays in time $(1 \mathrm{~h})$. Case 3 (W3) features multiple updrafts that weaken over time. Case 7 (W7) has shallower updrafts of maximum $0.5 \mathrm{~ms}^{-1}$ over $8 \mathrm{~h}$. To assess the impact of aerosols, experiments are conducted with variable drop number from 10 to $2000 \mathrm{~cm}^{-3}$. This spans the range from pristine to very polluted conditions.

In off-line tests, we estimate first the cloud albedo, and then divide albedo $(A)$ changes into contributions from (1) liquid water path (LWP), (2) cloud drop number concentration $\left(N_{\mathrm{c}}\right)$ and (3) cloud coverage $(C)$. To estimate albedo $(A)$ we make the assumption that

$A=C \cdot \tau /(\beta+\tau)$,

where $\beta=6.8, \tau=\alpha \cdot \mathrm{LWP}^{5 / 6} \cdot N_{\mathrm{c}}^{1 / 3}$ and $\alpha=0.19$ (Zhang et al., 2005, Eqs. 19-20). Strictly speaking the albedo should include a surface reflectance term, which over ocean would be $(1-C) \cdot A_{\mathrm{sfc}}$, where for ocean $A_{\mathrm{sfc}}=0.05$. For these idealized cases we assume $A_{\mathrm{sfc}}=0$. The change in albedo (dA) can then be represented as

$\Delta A=\frac{\mathrm{d} A}{\mathrm{~d} N_{\mathrm{c}}} \Delta N_{\mathrm{c}}+\frac{\mathrm{d} A}{\mathrm{dLWP}} \Delta \mathrm{LWP}+\frac{\mathrm{d} A}{\mathrm{~d} C} \Delta C+r$.

$C$ (cloud cover or cloud fraction) has one value for each simulation. $N_{\mathrm{c}}$ has one specified value for each simulation and LWP is an average over the simulation period. $r$ is a residual. The changes are discrete differences between simulations with different specified $N_{\mathrm{c}}$ for each case.

The idealized one-dimensional kinematic driver is designed to test different microphysical schemes in the same framework. Results of such idealized off-line tests are qualitatively useful for examining the relative importance of individual processes for ACI. We use them for illustration, and will use global sensitivity tests of the full GCM for quantification.

\subsection{Global sensitivity tests}

The MG2 scheme is implemented in version 5 of the Community Atmosphere Model (CAM5.3; Neale et al., 2010) as described by Gettelman et al. (2015). The MG2 scheme in CAM is coupled to aerosol activation on liquid (AbdulRazzak and Ghan, 2002) and ice (Liu et al., 2007) hydrometeors, and can also take specified number concentrations for liquid and ice. CAM5 features a modal aerosol model (Liu et al., 2012). The MG scheme has prognostic drop number with no minimum drop number. 
Table 1. Description of sensitivity tests used in the text, including the case short name (including the microphysics scheme used), a brief description, and the type of experiment. All tests are pairs of simulations as described in the text.

\begin{tabular}{lll}
\hline Case & Description & Type \\
\hline MG2 & Base case & \\
\hline MG2-2000-1750 & ACI with no human emissions & Emissions \\
MG2-1850-1750 & Pre-industrial vs. no human emissions & Emissions \\
MG2-Nat0.5 & MG2 with natural aerosol emissions $\times 0.5$ & Emissions \\
MG2-Nat2 & MG2 with natural aerosol emissions $\times 2$ & Emissions \\
\hline MG1 & Base case cloud microphysics & Activation \\
MG1-Hoose & New mixed phase ice nucleation & Mixed phase \\
MG2-Berg0.1 & MG2 with vapor deposition rate $\times 0.1$ & Mixed phase \\
MG1.5 & MG1 + different activation, MG2 tuning & Prog precipitation \\
MG2-NoER & MG2 without evaporation of rain number & Prog precipitation \\
MG2-CLUBB & New moist turbulence scheme & Coupling \\
MG2-NoLif & MG2 with lifetime effects removed & Lifetime \\
MG2-K2013 & MG2 with K2013 autoconversion & Autoconversion \\
MG2-SB2001 & MG2 with SB2001 autoconversion & Autoconversion \\
\hline
\end{tabular}

For the global model, we run simulations with specified climatological sea surface temperatures (SSTs) and greenhouse gases representing year 2000 conditions. We then vary aerosol emissions in two simulations for the year 2000 and 1850; differences represent only the effects of aerosol emissions. 1850 refers only to the aerosol emissions greenhouse gases and SSTs remain at year 2000 conditions. Simulations are $1.9^{\circ}$ latitude by $2.5^{\circ}$ longitude horizontal resolution, they are 6 years long, and the last 5 years are analyzed and are similar to previous work (Gettelman et al., 2012, 2015). Sensitivity tests are described below.

To understand the uncertainty in using 5 years of simulation, we performed an uncertainty analysis. This consisted of running the MG2 experiment out for 20 years (for 2000 and 1850 conditions). Analysis of separate 5-year periods indicates uncertainty of $0.08 \mathrm{Wm}^{-2}$ for ACI and long-wave $(\mathrm{LW}) /$ shortwave (SW) components (about $10 \%$ ) and within $0.04 \mathrm{Wm}^{-2}$ for direct effects relative to 20 -year means. We also performed nudged experiments where winds or winds and temperatures were fixed to a previous CAM simulation, but these produced slightly different cloud radiative effects, and thus slightly different quantitative values for ACI (different by $20-40 \%$ ). Qualitative patterns and zonal mean structure of ACI are similar to the free-running experiments.

In global simulations, ACI can be defined as the change in cloud radiative effects (CRE) in the LW and SW, where CRE are equal to the all sky top-of-atmosphere (TOA) radiative flux minus an estimate of what the clear-sky flux would be without clouds, but with the same state (temperature, humidity and surface structure). CRE are adjusted following Ghan et al. (2013) to use the "clean-sky" effects based on TOA fluxes estimated with a diagnostic call to the radiation code without aerosols. Results are similar, but with a slightly higher magnitude, to a direct estimate of ACI using CRE. Di- rect absorption and scattering by aerosols is also estimated by differencing the TOA radiative fluxes to TOA fluxes estimated with a diagnostic call to the radiation code without aerosols.

Table 1 describes the different sensitivity tests. As noted below, tests are motivated by previous studies identifying microphysical sensitivities. All tests are pairs of simulations with emissions of aerosols set to 2000 and 1850, except for the MG2-2000-1750 and MG2-1850-1750, which use different emissions years to explore different magnitudes of emissions changes. To explore how linear the changes in emissions are, we look at emissions without any human influence (no biomass burning, domestic or industrial emissions) and term this 1750 . We also explore modifying background natural emissions in both 1850 and 2000 by a factor of 0.5 or 2. These experiments test the impact of emissions (Carslaw et al., 2013), not cloud microphysics.

Tests also track the evolution of the cloud microphysics in CAM from MG1 (Morrison and Gettelman, 2008) to MG2 (Gettelman and Morrison, 2015). MG1.5 is an interim version that has (a) changes to the location where activated numbers are applied to before estimation of microphysical processes (which thickens the stratiform clouds) and (b) compensating increases in the threshold relative humidity for cloud formation to thin clouds back to radiative balance. The difference between MG1 and MG1.5 tests the changes to the activation scheme. The impact of prognostic precipitation is tested by the differences between MG2 and MG1.5.

Two experiments test sensitivity to mixed phase cloud processes. MG1-Hoose contains a representation of mixed phase ice nucleation that is tied to aerosols (Hoose et al., 2010), instead of the temperature-dependent scheme in MG1 (Meyers et al., 1992). This change tests the mixed phase ice scheme. The MG2-Berg0.1 simulations reduce the efficiency of the 

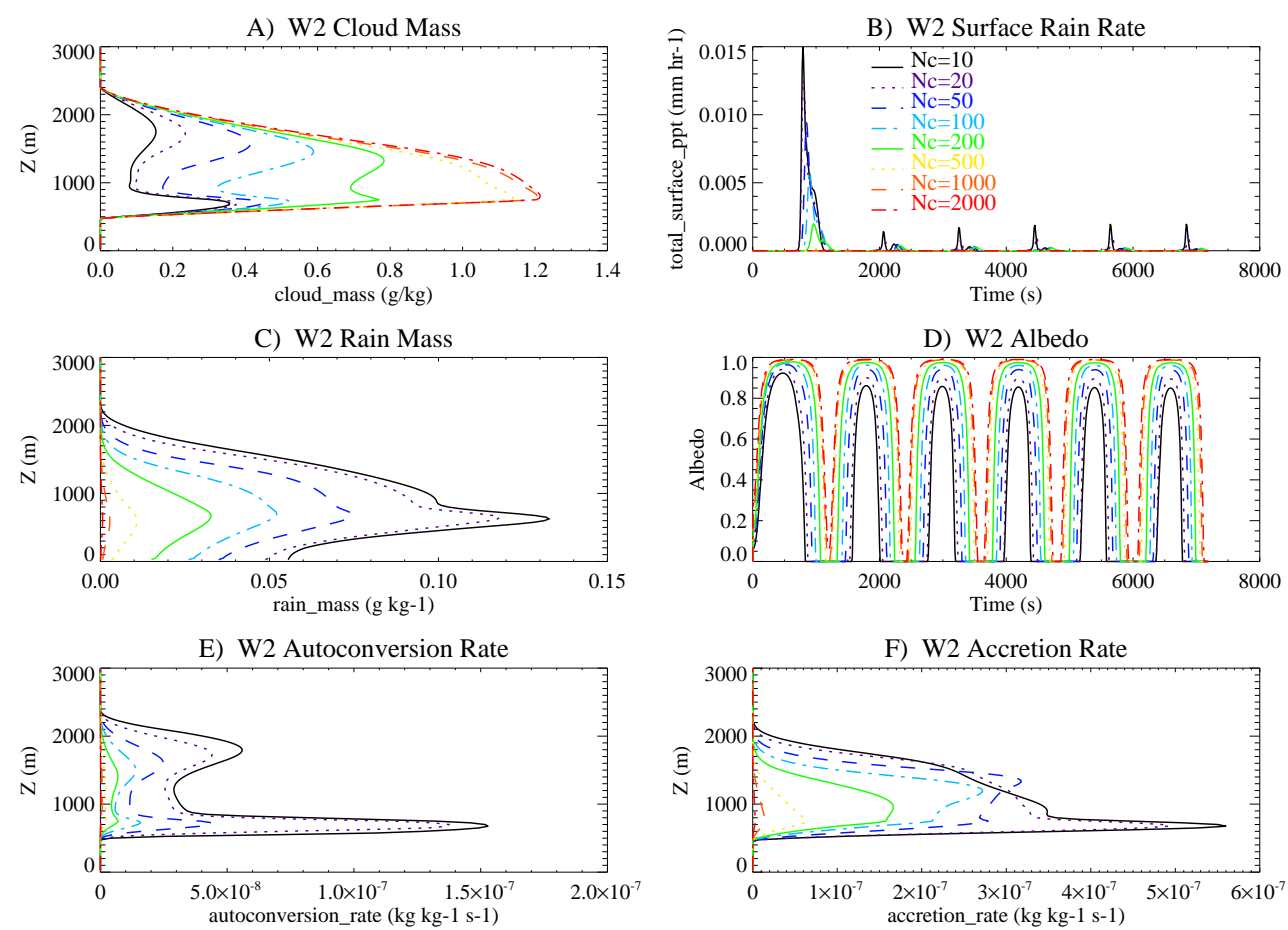

Figure 1. Warm 2 (W2) off-line tests of (a) time-averaged cloud mass $\left(\mathrm{g} \mathrm{kg}^{-1}\right)$, (b) time series of surface rain rate $\left(\mathrm{mm} \mathrm{h}^{-1}\right)$, (c) timeaveraged rain mass $\left(\mathrm{g} \mathrm{kg}^{-1}\right)$, (d) time series of albedo, time-averaged (e) autoconversion and (f) accretion rates $\left(\mathrm{kg} \mathrm{kg}^{-1} \mathrm{~s}^{-1}\right)$. Different colors correspond to different fixed cloud drop number concentrations.

vapor deposition process by a factor of 10 . This sensitivity test is motivated by the work of Korolev (2007) and Korolev (2008), who suggested that due to updraft rates in clouds at least half the time the vapor deposition rate may not apply. It is also motivated by tests in Lawson and Gettelman (2014) extending this to a large-scale model that would also assume inhomogeneity in a grid box, and found improvements in Antarctic radiative fluxes.

Perturbations to the MG2 microphysics itself are also explored by first, removing evaporation of rain number (MG2NoER) present in MG2 but not MG1, and then removing lifetime effects by fixing cloud drop numbers in autoconversion, sedimentation and freezing (MG2-NoLif). A fixed number of $100 \mathrm{~cm}^{-3}$ for liquid drops and $0.1 \mathrm{~cm}^{-3}$ for ice crystals is used. An additional simulation with $300 \mathrm{~cm}^{-3}$ for liquid drops yields quantitatively and qualitatively similar results. A simulation is performed changing the moist turbulence scheme and coupling to cloud microphysics using a higherorder closure scheme called Cloud Layers Unified By Binormals (CLUBB; Bogenschutz et al., 2013) in MG2-CLUBB (Gettelman et al., 2015). As noted in the introduction, several previous studies have focused on sensitivity of ACI to the autoconversion process. Accordingly, we alter the autoconversion scheme in the simulations MG2-K2013 (Kogan, 2013) and MG2-SB2001 (Seifert and Beheng, 2001).

These tests and the parameter values are motivated by previous work. Zhao et al. (2013) conducted a perturbed pa- rameter ensembles with a similar version of CESM and focused on radiative effects. However, Zhao et al. (2013) and other perturbed parameter ensembles have not focused on the radiative perturbations due to aerosols, and here the experiments are all pairs of simulations with pre-industrial and present-day aerosols.

\section{Results: off-line tests}

Figure 1 illustrates basic results from the off-line experiments with different specified drop numbers. As drop number increases, average cloud condensate mass increases (Fig. 1a) and the surface rain rate (Fig. 1b) and rain mass (Fig. 1c) drop rapidly to zero for $N_{\mathrm{c}}>500 \mathrm{~cm}^{-3}$. The cloud albedo (estimated using Eq. 1) increases substantially (Fig. 1d) for increasing drop number. The mechanism for the microphysical changes as described by Gettelman and Morrison (2015) is the decrease in the autoconversion rate with increasing drop number (Fig. 1e), which also causes decreases in accretion rate as the rain mass decreases (Fig. 1f).

The W2 case initiates two separate layers of cloud in subsequent updrafts after the first. There is larger autoconversion and accretion in the lower layer, creating the peaks in cloud mass (Fig. 1a), rain mass (Fig. 1c), autoconversion (Fig. 1e) and accretion (Fig. 1f). Autoconversion and accretion are not 

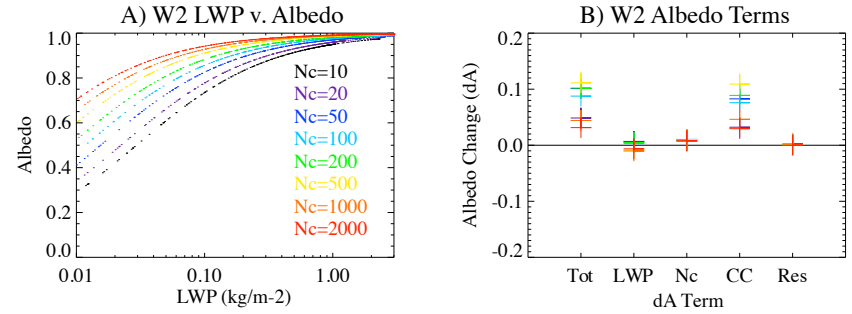

Figure 2. (a) Liquid water path (LWP) vs. albedo and (b) albedo change by different sensitivity $(\mathrm{d} A)$ terms from the oscillating warm rain case (W2). Different colors correspond to different fixed cloud drop number concentrations. The albedo terms in (b) correspond to the total (Tot) change and the portion due to LWP, number concentration $\left(N_{\mathrm{c}}\right)$, cloud coverage $(\mathrm{CC})$ and a residual (Res).

increasing at the bottom of the cloud. Instead, this is a different layer of cloud not seen as separate in the time average.

The impact of these changes on albedo is highlighted in Fig. 2. The albedo increases with higher drop numbers (Fig. 1d). This actually changes the slope of the relationship between albedo and liquid water path (LWP), seen in Fig. 2a. At low liquid water paths, the albedo changes are more sensitive to LWP. In Fig. 2a, the slope (dA/dLWP) is constant at low LWP, but shifts to reduced sensitivity at high LWP. Using the decomposition of the albedo change in Eq. (2), we can break down the change between pairs of simulations (e.g., $N_{\mathrm{c}}=20$ to $N_{\mathrm{c}}=10$ ) by the different components: the total change in albedo (Tot), the change due to LWP $(\mathrm{d} A / \mathrm{dLWP} \times \Delta \mathrm{LWP})$, the change due to changes in $N_{\mathrm{c}}$ $\left(\mathrm{d} A / \mathrm{d} N_{\mathrm{c}} \times \Delta N_{\mathrm{c}}\right)$ and the change due to cloud cover changes $(\mathrm{d} A / \mathrm{d} C \times \Delta C)$. Differences are calculated based on the difference in time-averaged albedo between two simulations. The residual is the difference between the total and the sum of the three terms, which is small. In the W2 case with an oscillating updraft, the change in cloud coverage dominates the albedo change (Fig. 2b). Note that cloud mass (Fig. 2a) is changing along with cloud coverage (Fig. 2d). Most of the difference in Fig. 2a (cloud mass) is change to the extent of clouds with the same in-cloud water content; hence for this case, the coverage is identified as being critical.

Figure 3 illustrates the same set of albedo sensitivity terms for four different cases. The mean and 1 standard deviation of pairs of adjacent drop numbers (seven pairs from eight values of drop number) is indicated by the error bar range and midpoint, and the median is shown as a diamond. The W2 case from Fig. 2b is illustrated in Fig. 3b (black line), where cloud coverage dominates the change in albedo. Some cases have mostly small differentials for the terms, and only some values of $N_{\mathrm{c}}$ have large differentials, so the median is often near zero but the average (dominated by 1-2 cases) is non-zero. The base case (black) is the basic case using the autoconversion scheme of Khairoutdinov and Kogan (2000), hereafter KK2000. KK2000 represent autoconversion from a fit to cloud-resolving model experiments as a function of the cloud mass and an inverse function of drop number; the autoconversion rate $\left(A_{u}\right)$ is $A_{u}=1350 q_{c}^{2.47} N_{\mathrm{c}}^{-1.79}$. This is also true for W1 (Fig. 3a), with lower sensitivity. However, the LWP and $N_{\mathrm{c}}$ changes are important in the W3 and W7 cases (Fig. $3 \mathrm{c}$ and d). These are weaker multiple updraft cases.

Also shown in Fig. 3 are three additional sets of experiments where the microphysics has been modified to limit the lifetime effects. This has been done by specifying a constant fixed drop number of $100 \mathrm{~cm}^{-3}$ to (a) the autoconversion scheme $(\mathrm{Au})$, and (b) the sedimentation (Sed) or both (NoLif). Different drop numbers ranging from 10 to $2000 \mathrm{~cm}^{-3}$ are used for all other processes in the microphysics. The NoLif cases (dark blue in Fig. 3) are similar to the Au cases (green: autoconversion effects only) indicating that autoconversion is the dominant process for lifetime effects. In particular, removing the lifetime effects by specifying the number concentration going into autoconversion removes the cloud coverage effects in the W2 case (Fig. 3b), and perhaps more significantly removes the LWP effects on albedo in all cases. This leaves only the drop number effects on albedo. Thus, for some cases with partial cloud cover (e.g., like the W2 case in Fig. 3b), lifetime effects are important for cloud cover changes, but in all cases the effect of autoconversion in drop number seems to impact LWP.

Recognizing that the representation of autoconversion is important, we explore two alternatives. Kogan (2013), hereafter K2013, use a similar representation as KK2000 and derive $A_{u}=7.90 \times 10^{10} q_{c}^{4.22} N_{\mathrm{c}}^{-3.01}$. Seifert and Beheng (2001), hereafter SB2001, derive expressions for autoconversion and accretion that include the rain water mixing ratio as a proxy for large cloud droplets to describe the broadening of the drop size distribution and reduce the efficiency of accretion in the early stage of the rain formation. We have implemented both of these parameterizations into the microphysics scheme.

Figure 4 shows the impact of the SB2001 scheme in the single updraft W1 case with a fixed drop number of $200 \mathrm{~cm}^{-3}$. Relative to KK2000 (black), the use of SB2001 (red) for autoconversion results in higher cloud mass (Fig. 4a), significantly less precipitation (Fig. 4b) and delayed and smaller rain formation (Fig. 4c) and rain number concentration (Fig. 4d). Autoconversion (Fig. 4e) is delayed, but has a higher magnitude, and accretion is also delayed (Fig. 4f), but has a lower magnitude; the changes are significant. At lower number concentrations the differences are smaller, and they are larger at higher number concentrations (not shown).

The impact of these changes on the albedo changes in the off-line driver cases is illustrated in Fig. 5. KK2000 are the same as the base case in Fig. 3. Results are similar with different autoconversion schemes in case W1 (single updraft: Fig. 5a) and case W7 (shallow updraft: Fig. 5d). In case W2, there is a significant reduction in the cloud coverage and LWP effects on albedo with SB2001 (Fig. 5b); furthermore, there is a significant reduction in the LWP effect in case W3 

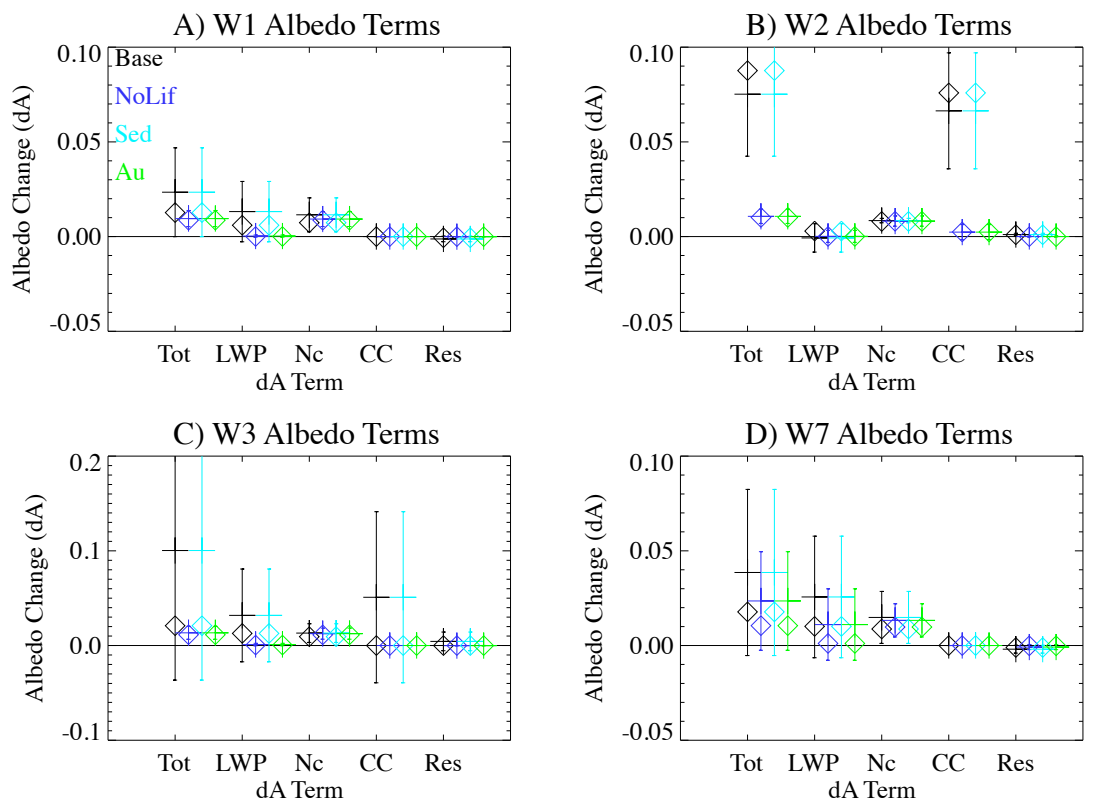

Figure 3. Albedo change by different sensitivity (dA) terms from different warm rain cases. (a) Warm 1, (b) warm 2, (c) warm 3 and (d) warm 7. Albedo terms in each panel correspond to the total (Tot) change and the portion due to liquid water path (LWP), number concentration $\left(N_{\mathrm{c}}\right)$, cloud coverage (CC) and a residual (Res); the standard case (Base) is in black. Also shown are the no lifetime effects case (dark blue) and the two components of the lifetime effect: sedimentation (cyan) and autoconversion (green).

for SB2001 and K2013 (Fig. 5c), which is compensated for in-cloud cover changes. Autoconversion matters in the cases with multiple updrafts where cloud coverage is most sensitive (W2 and W3), and it matters more for the oscillating (W2) than decaying (W3) or weak (W7) updraft case. This is likely because with a limited temporal updraft the timing of precipitation matters.

\section{Results: global sensitivity tests}

Global sensitivity tests with CESM explore how different perturbations to cloud microphysics impact ACI. All tests are pairs of simulations with emissions of aerosols set to 2000 and 1850, except for the 2000-1750 and 1850-1750 cases, which use different emissions years to explore different magnitudes of emissions changes. The experiments described in Sect. 2.2 and Table 1 fall into several categories chosen to span key sensitivities in different microphysical processes. These are based on a number of previous studies that have identified these different processes as critical for the interaction of aerosols with clouds. These studies are highlighted below. The different processes include (1) aerosol activation (MG1) (Ghan et al., 2013; Carslaw et al., 2013), (2) precipitation (MG1.5, NoER: evaporation of rain) (Wood et al., 2009; Jiang et al., 2010), (3) mixed phase (Berg0.1: vapor deposition and Hoose: ice nucleation) (Hoose et al., 2010; Lawson and Gettelman, 2014), (4) autoconversion (lifetime effects and two other autoconversion schemes: K2013, SB2001)
(Wood et al., 2009; Gettelman et al., 2013), (5) coupling to other schemes (CLUBB) (Guo et al., 2011) and (6) natural emissions (Nat 0.5 and Nat2) (Carslaw et al., 2013). In particular, the range of natural aerosol emissions is identical to the range in Carslaw et al. (2013).

The radiative changes between the pairs of simulations in each sensitivity experiment are indicated in Table 2 . ACI use clean-sky CRE as discussed by Ghan et al. (2013). Differences in microphysical quantities are in Table 3. For Table 3 and the figures, simulated cloud-top liquid microphysical values are estimated by taking the highest level (first from the top of the model going down) where cloud condensate is found. This is done at each point in the model and averaged over those points which are non-zero. The values and figures in the text come from these simulations. The net CRE for all the simulations (Table 3) is broadly similar, within about $\pm 1 \mathrm{Wm}^{-2}$, except for the MG2-CLUBB simulation, which has a different balance of CRE, drop number and effective radius (Table 3).

The radiative changes between the pairs of simulations in each sensitivity experiment are indicated in Fig. 6a. ACI are defined as the change in clean-sky cloud radiative effect ( $\triangle \mathrm{CRE}$ ) between pairs of simulations with different aerosol emissions (Ghan et al., 2013). Directly using CRE yields similar quantitative $(\%)$ differences between simulations. ACI for $2000-1850$ emissions are $-1.57 \mathrm{Wm}^{-2}$ with MG1, $-1.13 \mathrm{Wm}^{-2}$ with MG1.5 and $-0.98 \mathrm{Wm}^{-2}$ with MG2 (Table 2). Maximum ACI are found in Northern Hemisphere midlatitudes (Fig. 6a), where most anthropogenic emissions 

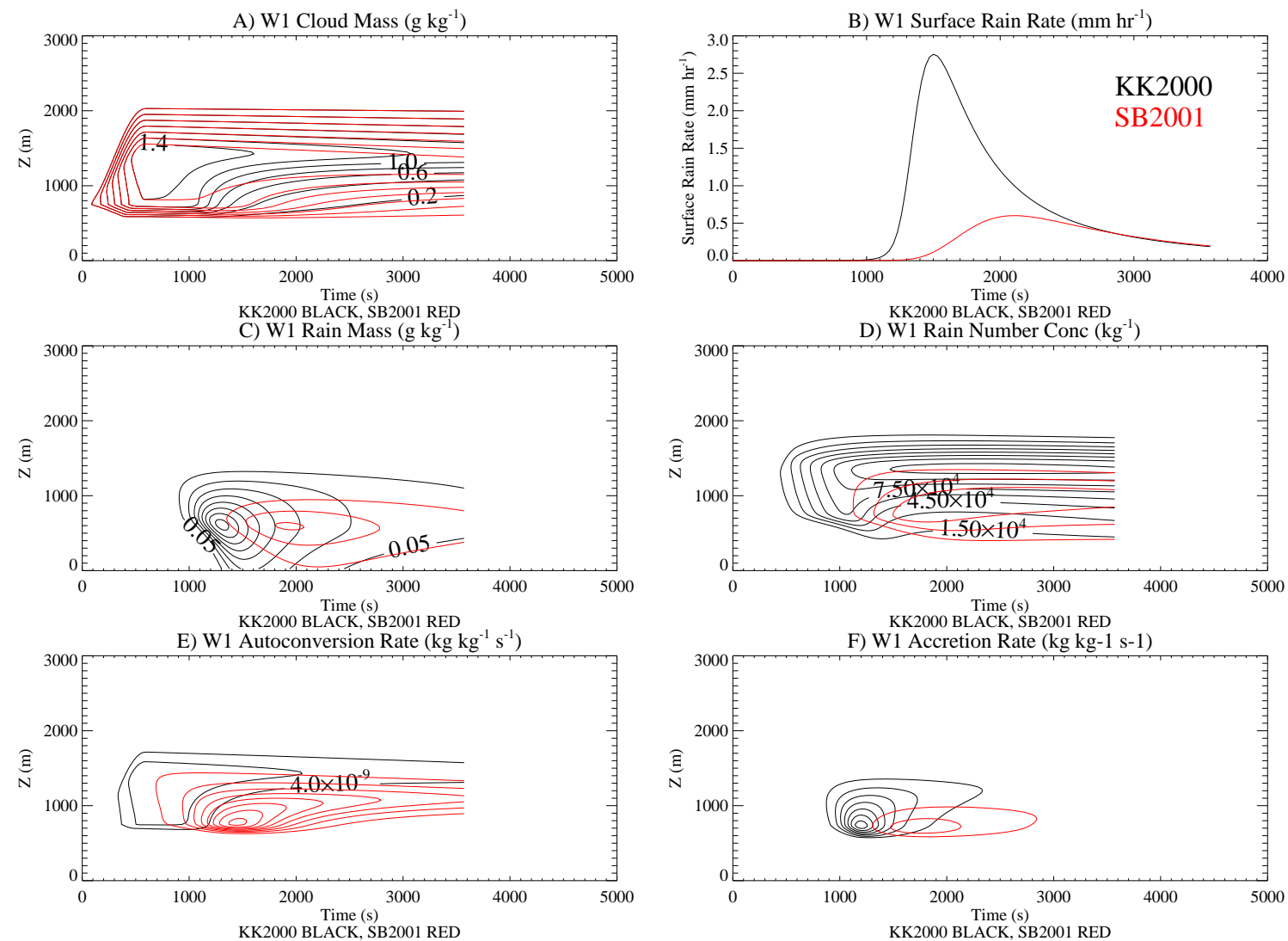

Figure 4. Warm 1 (W1) single updraft case results with cloud drop number concentration of $200 \mathrm{~cm}^{-3}$ for (a) cloud liquid mass (contour interval $0.2 \mathrm{~g} \mathrm{~kg}^{-1}$ ), (b) surface precipitation rate, (c) warm rain mass (contour interval $0.05 \mathrm{~g} \mathrm{~kg}^{-1}$ ) and (d) rain number (contour interval $\left.1.5 \times 10^{4} \mathrm{~kg}^{-1}\right)$, (e) autoconversion rate (contour interval $4 \times 10^{-9} \mathrm{~kg}^{-1}$ ) and (f) accretion rate (contour interval $3 \times 10^{-9} \mathrm{~kg}^{-1}$ ) from MG2 with KK2000 (black) and SB2001 (red).
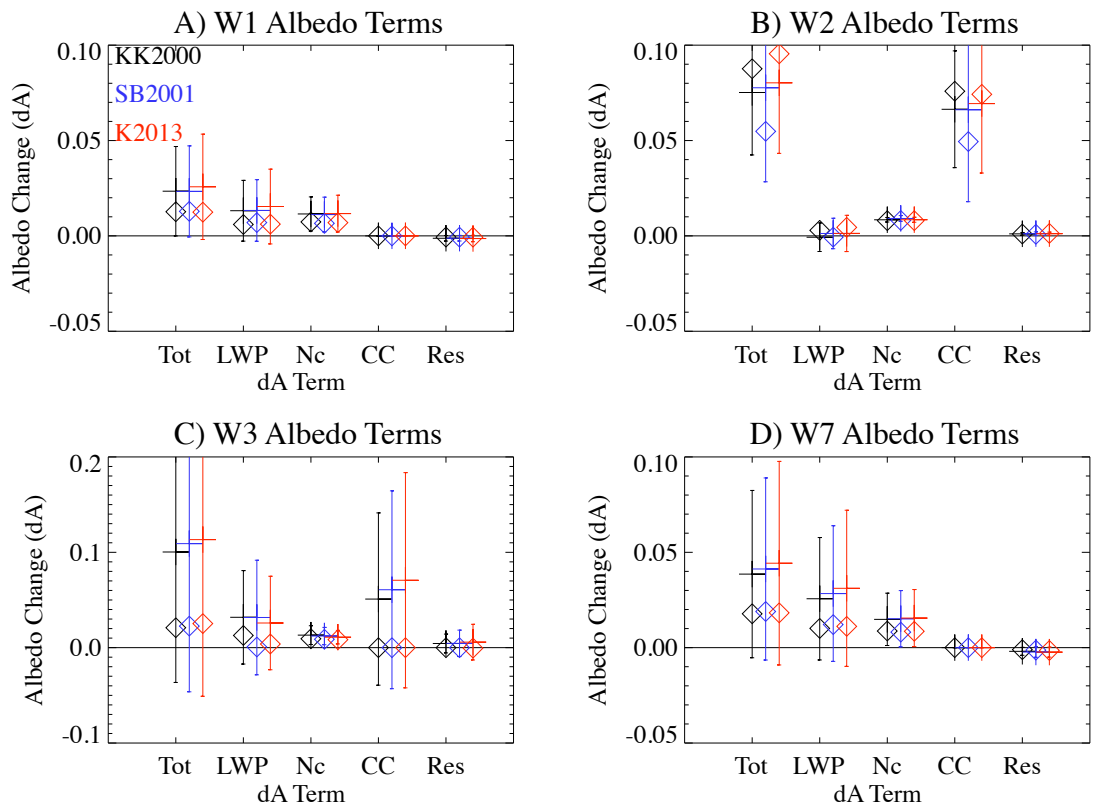

Figure 5. As for Fig. 3 but for standard case (KK2000) in black and two other autoconversion schemes: SB2001 (blue) and K2013 (red); see text for details. 
Table 2. Radiative impacts of ACI for the different sensitivity tests. Change in top-of-atmosphere (TOA) flux ( $\triangle \mathrm{R})$, ACI as change in cleansky cloud radiative effect $(\triangle \mathrm{CRE})$, and its long-wave (LW) and shortwave (SW) components following Ghan et al. (2013). Direct effects (DE) of aerosols as described in the text. Finally, a residual ( $\mathrm{Res}=\mathrm{ACI}+\mathrm{DE}-\Delta \mathrm{R})$.

\begin{tabular}{lrrrrrr}
\hline Case & $\begin{array}{r}\Delta \mathrm{R} \\
\mathrm{Wm}^{-2}\end{array}$ & $\begin{array}{r}\mathrm{ACI} \\
\mathrm{Wm}^{-2}\end{array}$ & $\begin{array}{r}\Delta \mathrm{LW} \mathrm{CRE} \\
\mathrm{Wm}^{-2}\end{array}$ & $\begin{array}{r}\Delta \mathrm{SW} \text { CRE } \\
\mathrm{Wm}^{-2}\end{array}$ & $\begin{array}{r}\mathrm{DE} \\
\mathrm{Wm}^{-2}\end{array}$ & $\begin{array}{r}\text { Res } \\
\mathrm{Wm}^{-2}\end{array}$ \\
\hline MG1 & -1.59 & -1.57 & 0.44 & -2.01 & -0.06 & 0.05 \\
MG1-Hoose & -1.61 & -1.51 & 0.81 & -2.32 & -0.05 & -0.04 \\
MG1.5 & -1.22 & -1.13 & 0.23 & -1.36 & -0.07 & -0.02 \\
MG2 & -1.08 & -0.98 & 0.15 & -1.14 & -0.07 & -0.03 \\
\hline MG2-2000-1750 & -1.29 & -1.23 & 0.21 & -1.44 & -0.08 & 0.01 \\
MG2-1850-1750 & -0.21 & -0.25 & 0.06 & -0.30 & -0.01 & 0.04 \\
MG2-Nat0.5 & -1.46 & -1.24 & 0.21 & -1.44 & -0.11 & -0.12 \\
MG2-Nat2 & -0.87 & -0.68 & 0.18 & -0.86 & 0.09 & -0.28 \\
\hline MG2-CLUBB & -1.43 & -1.56 & -0.05 & -1.50 & -0.02 & 0.14 \\
MG2-NoLif & -0.78 & -0.72 & 0.36 & -1.08 & -0.08 & 0.02 \\
MG2-K2013 & -1.21 & -1.11 & 0.21 & -1.32 & -0.08 & -0.01 \\
MG2-SB2001 & -0.70 & -0.77 & 0.46 & -1.23 & -0.05 & 0.12 \\
MG2-NoER & -1.19 & -1.11 & 0.29 & -1.39 & -0.08 & 0.00 \\
MG2-Berg0.1 & -1.53 & -1.41 & 0.26 & -1.67 & -0.06 & -0.06 \\
\hline
\end{tabular}

occur. Northern Hemisphere midlatitudes are also where the largest changes to LWP (Fig. 6b) and cloud-top drop number concentration $\left(\Delta N_{\mathrm{c}}\right.$, Fig. $\left.6 \mathrm{c}\right)$ occur. Interestingly the changes to cloud-top drop effective radius ( $\Delta$ Re, Fig. 6 d) spread farther into high latitudes.

Most of the ACI are due to the shortwave (SW: solar) wavelengths: brighter clouds (Table 2). However, there is a significant component of positive ACI in the long-wave (LW: terrestrial) wavelengths. This is a result of two factors. First is the effect of aerosols on cirrus clouds, where more ice nuclei are formed, and clouds become more opaque in the long wave than they become brighter in the shortwave (Gettelman et al., 2012). Second is a compensation effect between LW and SW for cirrus clouds due to movement of cirrus cloud fraction in the tropics. The second effect accounts for a good amount of the variance in the magnitude of the LW and SW between sensitivity tests: increases in LW CRE are compensated for by decreases in (increased magnitude of negative) SW CRE.

To understand how ACI change with cloud microphysics, we explore how the radiative effects of ACI are related to microphysical properties strongly related to radiative effects. Figure 7 illustrates some of the broad-scale patterns across the simulations, by relating the changes in cloud radiative effect ( $\mathrm{ACI}=\triangle \mathrm{CRE}$ ) to other properties of the simulations, namely, changes to LWP (in percent, Fig. 7a), changes to the cloud-top drop number concentration (Fig. 7b), changes to cloud-top effective radius (Fig. 7c) or changes in total (vertically integrated) cloud coverage or fraction (Fig. 7d). There is a strong correlation between $\triangle$ LWP and ACI (Fig. 7a). The only simulations that differ from the correlation are those with CLUBB and the simulation without lifetime ef- fects (NoLif). The CLUBB simulation has a very different coupling of large-scale condensation and cloud microphysics, as described by Gettelman et al. (2015), where the microphysics is sub-stepped with the CLUBB condensation scheme six times in each time step. The NoLif simulation has basically no change in LWP, which is consistent with the off-line KiD tests with a similar formation. The ACI go from -0.98 (MG2) to $-0.72 \mathrm{Wm}^{-2}$ (NoLif) in Table 2. There is no correlation between the change in cloud-top drop number (Fig. 7b) or effective radius (Fig. 7c) and ACI. Changes in effective radius are negative, indicating smaller drops in the present with more aerosols than in the past (pre-industrial). There are small changes in total cloud cover that correlate slightly with ACI (Fig. 7d), but mostly because there are large changes (increases in cloud coverage) in three simulations with large ACI (CLUBB, MG1, MG1-Hoose).

The simulation without lifetime effects (NoLif) actually has the largest change (reduction) in averaged drop radius (Fig. 7c), despite no change in LWP (Fig. 7a) and small changes in ACI. Most simulations have an increase in cloud drop number of $\sim 30 \mathrm{~cm}^{-3}$. This is an interesting result because many models still prescribe the radiative effects of aerosols by linking aerosol mass to a change in cloud drop number or size; on the contrary, in CAM the clearest effects seem to be due to LWP, though ACI are non-zero even if $\Delta \mathrm{LWP}=0$.

The following sub-sections detail each of the dimensions of changes to understand the magnitude of the effects.

\subsection{Activation}

The change to drop activation (moving it before the cloud microphysical process rates) is seen in the difference between 
A) Zonal Mean ACI

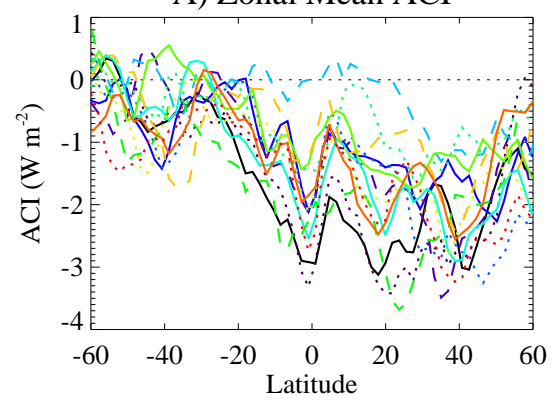

C) Zonal Mean $\Delta \mathrm{Nc}$

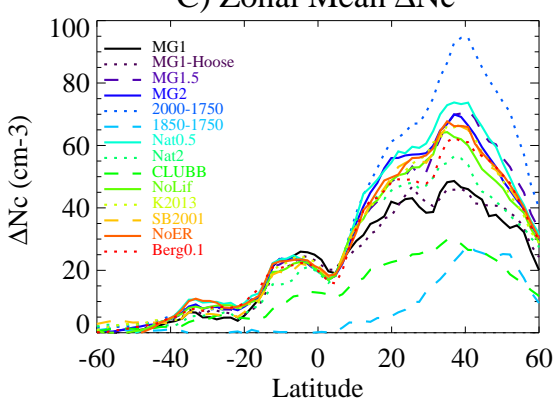

B) Zonal Mean $\Delta$ LWP

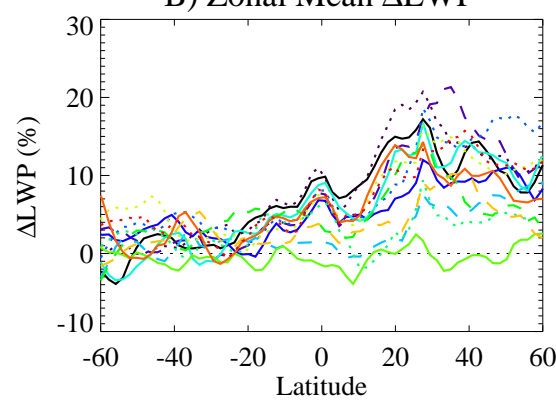

D) Zonal Mean $\Delta \mathrm{Re}$

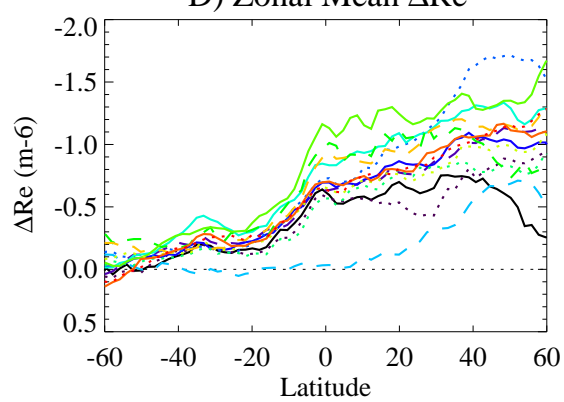

Figure 6. Zonal mean (a) ACI (change in CRE, $\mathrm{Wm}^{-2}$ ), (b) percent change in LWP, (c) change in cloud-top drop number concentration $\left(\Delta N_{\mathrm{c}}, \mathrm{cm}^{-3}\right)$ and $(\mathbf{d})$ change in cloud-top effective radius $\left(\Delta \mathrm{Re}, \mathrm{m}^{-6}\right)$ for different sensitivity tests noted with colors and different line styles.
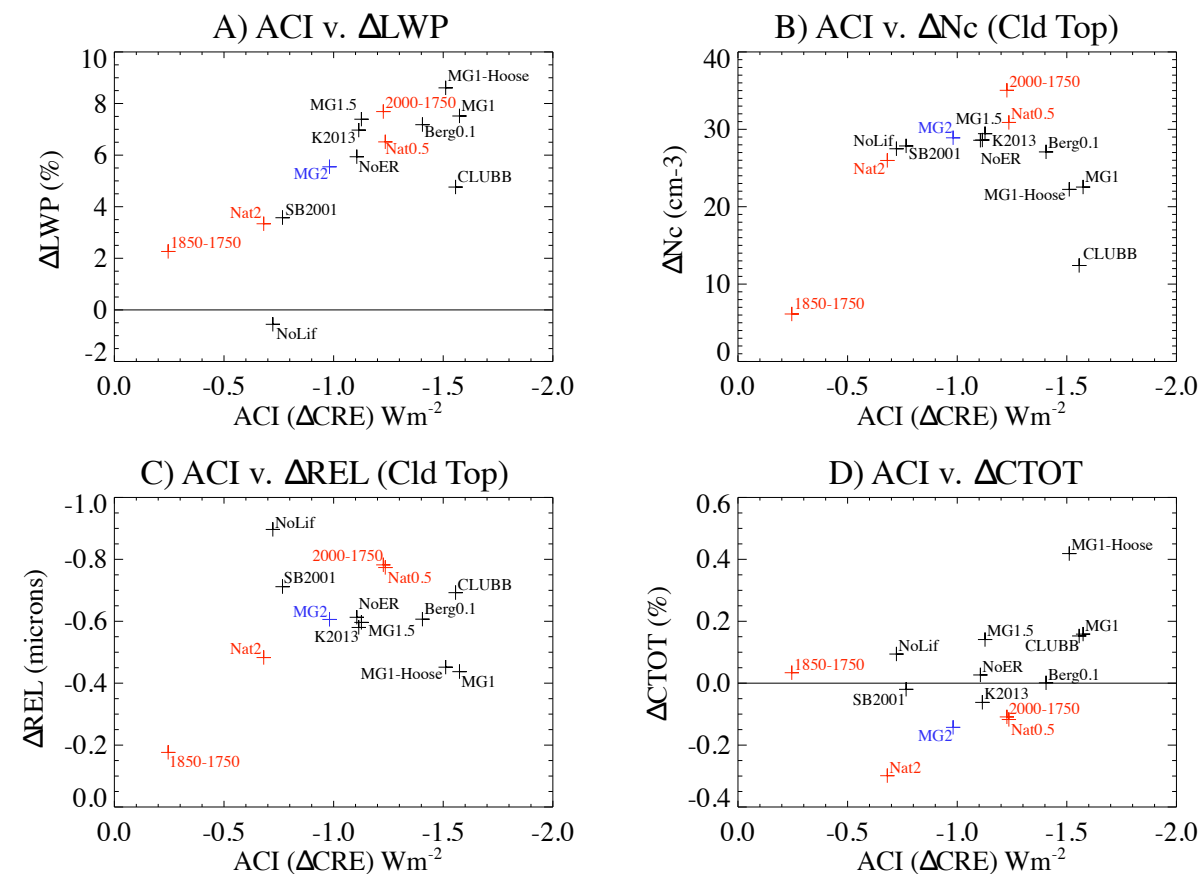

Figure 7. ACI (change in CRE, $\mathrm{Wm}^{-2}$ ) vs. (a) percent change in LWP, (b) change in cloud-top drop number concentration $\left(\Delta N_{\mathrm{c}}, \mathrm{cm}^{-3}\right)$, (c) change in cloud-top effective radius $\left(\triangle \mathrm{REL}, \mathrm{m}^{-6}\right.$ or microns) and (d) change in total cloud coverage (CTOT, \%) for different sensitivity tests. Red colors are tests of different emissions, blue is the base MG2 case and black is the other sensitivity tests. 
Table 3. Microphysical impact of different sensitivity tests. Mean CRE, change in LWP (\%), mean LWP, change in cloud-top (CT) effective radius (REL), mean CT REL, change in CT drop number concentration $(\mathrm{Nc})$ and mean $\mathrm{CT} N_{\mathrm{c}}$.

\begin{tabular}{lrrrrrrr}
\hline Case & $\begin{array}{r}\text { CRE } \\
\mathrm{Wm}^{-2}\end{array}$ & $\begin{array}{r}\Delta \text { LWP } \\
\%\end{array}$ & $\begin{array}{r}\text { LWP } \\
\mathrm{g} \mathrm{m}^{-2}\end{array}$ & $\begin{array}{r}\Delta \text { REL (CT) } \\
\mathrm{m}^{-6}\end{array}$ & $\begin{array}{r}\mathrm{REL}(\mathrm{CT}) \\
\mathrm{m}^{-6}\end{array}$ & $\begin{array}{r}\Delta \mathrm{Nc}(\mathrm{CT}) \\
\mathrm{cm}^{-3}\end{array}$ & $\begin{array}{r}\mathrm{Nc}(\mathrm{CT}) \\
\mathrm{cm}^{-3}\end{array}$ \\
\hline MG1 & -28.0 & 7.5 & 44.6 & -0.4 & 9.5 & 22.5 & 89.0 \\
MG1-Hoose & -28.4 & 8.6 & 46.2 & -0.5 & 9.5 & 22.2 & 88.6 \\
MG1.5 & -29.8 & 7.4 & 45.0 & -0.6 & 8.8 & 29.4 & 110.6 \\
MG2 & -27.9 & 5.5 & 39.4 & -0.6 & 9.0 & 28.9 & 107.2 \\
\hline MG2-2000-1750 & -27.9 & 7.7 & 39.4 & -0.8 & 9.0 & 35.0 & 107.2 \\
MG2-1850-1750 & -27.2 & 2.3 & 37.2 & -0.2 & 9.6 & 6.1 & 78.3 \\
MG2-Nat0.5 & -27.6 & 6.5 & 38.2 & -0.8 & 9.2 & 30.9 & 98.6 \\
MG2-Nat2 & -28.4 & 3.3 & 40.3 & -0.5 & 8.6 & 26.0 & 119.8 \\
\hline MG2-CLUBB & -25.6 & 4.8 & 40.1 & -0.7 & 11.3 & 12.4 & 59.1 \\
MG2-NoLif & -28.7 & -0.6 & 47.7 & -0.9 & 9.4 & 27.5 & 107.9 \\
MG2-K2013 & -27.8 & 7.0 & 37.6 & -0.6 & 8.9 & 28.6 & 107.4 \\
MG2-SB2001 & -28.3 & 3.6 & 44.6 & -0.7 & 9.2 & 27.9 & 109.2 \\
MG2-NoER & -28.2 & 5.9 & 39.9 & -0.6 & 9.0 & 28.6 & 106.9 \\
MG2-Berg0.1 & -28.7 & 7.2 & 44.0 & -0.6 & 8.8 & 27.1 & 101.7 \\
\hline
\end{tabular}

MG1 vs. MG1.5. This is a substantial reduction in ACI from -1.57 to $-1.13 \mathrm{Wm}^{-2}$ or $28 \%$ (Table 2). The likely cause is that by activating the number first, other processes in the microphysics act on the revised number, and this likely buffers the changes in the indirect effects (Stevens and Feingold, 2009). Note that there is basically no difference in the LWP change between MG1 and MG1.5 (Table 3). Effects are not simply linear, however, since MG1.5 with lower ACI has a larger $\Delta \mathrm{REL}$ and $\Delta N_{\mathrm{c}}$.

\subsection{Prognostic precipitation and rain evaporation}

The major scientific changes between MG1.5 (MG1 with the activation change) and MG2 as described by Gettelman and Morrison (2015) are the addition of prognostic precipitation and the addition of evaporation of number when rain evaporates. The latter change to evaporation of rain number actually does seem to make a difference: a reduction in ACI (Table 2) due to a reduction in $\triangle$ LWP (Table 3). The total reduction between MG1.5 and MG2 is -1.13 to $-0.98 \mathrm{Wm}^{-2}$, or about $14 \%$. This occurs through reductions in the $\triangle \mathrm{LWP}$ (Table 3), especially between 10 and $60^{\circ} \mathrm{N}$ latitude (Fig. 6b).

\subsection{Mixed phase clouds}

Two different sets of experiments were conducted to look at the impact of altering mixed phase clouds. The changes in MG1-Hoose make the simulations sensitive to anthropogenic aerosols in the mixed phase regime where they were not before. This causes increases in the magnitude of the LW and SW components of ACI (Table 2), but a small change in the net ACI $(-4 \%)$. The sensitivity of LWP goes up ( $\triangle$ LWP: Table 3). This experiment has the largest LW ACI, which is expected since it adds ACI in the mixed phase cloud regime between 0 and $-20^{\circ} \mathrm{C}$, which will have a significant effect on the $\mathrm{LW}$ radiation.

The second experiment used the MG2 configuration to reduce the efficiency of the vapor deposition onto ice (Bergeron-Findeisen process) by a factor of 10. This simulates inhomogeneity in cloud liquid and ice (or effectively inhomogeneity for in-cloud supersaturation or vertical velocity) that does not effectively mix liquid and ice. Korolev (2008) noted uncertainties of at least a factor of 2 in vapor deposition rates based on small-scale cloud dynamics, and Lawson and Gettelman (2014) found better agreement with Antarctic mixed phase clouds when vapor deposition was reduced by a factor of 100 . We picked a value between these limits for a sensitivity test. The reduction of vapor deposition increases the mean LWP and slightly decreases $\triangle$ LWP (Table 3). The stronger long-wave and shortwave components with more liquid likely lead to an increased magnitude in ACI (Table 2) of $+45 \%$, but the exact mechanism is unclear.

\subsection{Autoconversion and lifetime effects}

As in Sect. 3, we can also explore the sensitivity of the microphysics to autoconversion scheme. Gettelman et al. (2013) noted that the description of autoconversion and accretion matters for ACI, consistent with a series of previous studies (Menon et al., 2002; Rotstayn and Liu, 2005; Penner et al., 2006; Wang et al., 2012). One of the reasons for lower ACI in MG2 is due to the reduction of the ratio of autoconversion to accretion (more accretion and less autoconversion) with prognostic rain in MG2 (Gettelman et al., 2015).

Here we explore the impact of different autoconversion schemes on ACI. The K2013 scheme actually slightly increases the ACI over MG2 with KK2000 (Table 2), again 
A) $2000-1850 \Delta \mathrm{TOA}$ MG2

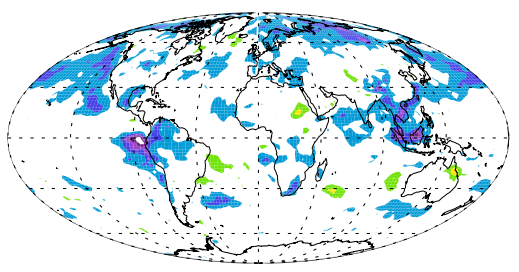

B) $2000-1850 \Delta \mathrm{TOA}$ NoLif

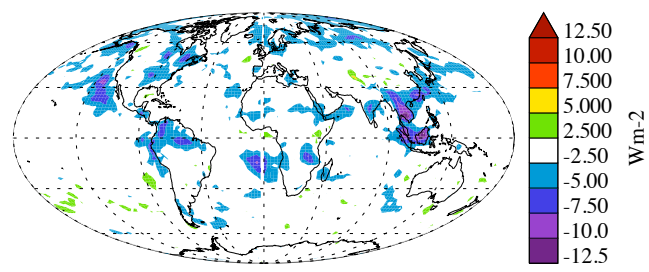

Figure 8. ACI as the total change in the top-of-atmosphere clean-sky cloud radiative effect (CRE) between simulations with 2000 and 1850 aerosol emissions for (a) base (MG2) and (b) no lifetime effect (NoLif) cases.

consistent with an increase in $\triangle$ LWP (Table 3). Conversely, the SB2001 scheme, with a smaller $\triangle \mathrm{LWP}$, reduces ACI from -0.98 to $-0.77 \mathrm{Wm}^{-2}$, or $22 \%$, and the NoLif simulation reduces ACI to $-0.72 \mathrm{Wm}^{-2}$ (nearly $-30 \%$ ) largely through more compensation between LW and SW effects; i.e., larger LW effects, indicating clouds with cold cloud tops may have higher LW emissivity. This indicates that the lifetime effects themselves may approach one-third of ACI (the total change in radiative flux changes from -1.04 in MG2 to -0.78 in the NoLif simulation, a reduction of $33 \%$ ). The lifetime effects are not that sensitive to the drop number threshold chosen. Results of a NoLif simulation with $300 \mathrm{~cm}^{-3}$ rather than $100 \mathrm{~cm}^{-3}$ for liquid drops yield similar results for $\Delta \mathrm{R}$ or $\mathrm{ACI}$.

The regional pattern of ACI, based on the total change in top-of-atmosphere fluxes, is illustrated in Fig. 8 for (a) the base MG2 case and (b) the NoLif case. The average local standard deviation of annual TOA flux is about $3 \mathrm{Wm}^{-2}$, so Fig. 8 shows regions with differences larger than 1 standard deviation. ACI effects are mostly in the Northern Hemisphere, and mostly over the oceans. There are some tropical effects in Southeast Asia and off the equatorial eastern Pacific, the latter due to anthropogenic emissions over the Amazon. The removal of lifetime effects in Fig. 8b indicates they are strong over the Northern Hemisphere midlatitude storm tracks, especially in the North Pacific. Lifetime effects also are strong in the equatorial eastern Pacific. Lifetime effects do not seem to impact the stratocumulus region off the coast of California, which has strong ACI without lifetime effects.

The effect of autoconversion and accretion is illustrated in Fig. 9. Figure 9 shows autoconversion and accretion rates and their ratio as a function of LWP. The figure compares results to estimates based on observations from the VOCALS campaign in the southeastern Pacific (see the corrigendum to Gettelman et al. (2013) for more details). Note that the rates are estimated from using observations to approximate the results of the stochastic collection equation, and may not be exactly comparable to the model simulations. The slope of the curves with LWP is probably the most relevant comparison. The figure represents $60^{\circ} \mathrm{S}-60^{\circ} \mathrm{N}$ averages for all liquid clouds treated by the stratiform cloud scheme, so it does not include convective clouds. A similar figure for just the south- eastern Pacific region yields similar results, but not as good statistics.

Accretion rates (Ac) are well represented in MG2 with the KK2000 autoconversion (Fig. 9c), but autoconversion rates $\mathrm{Au}$ ) at low LWP are very large (Fig. 9b), leading to a low Ac / Au ratio (Fig. 9). With the SB2001 scheme, accretion is high at low LWP, and autoconversion is 2 orders of magnitude lower. Autoconversion in particular is much closer to estimates from VOCALS (Terai et al., 2012). The result is a higher Ac / Au ratio, which may be too high at low LWP. The K2013 scheme (cyan in Fig. 9) yields similar results to KK2000: autoconversion is almost the same, and accretion is a little bit higher. The no lifetime simulation (green in Fig. 9) has accretion rates similar to KK2000, but lower autoconversion rates due to fixing the drop number in the autoconversion scheme. The no lifetime simulation has perhaps the closest representation to the Ac / Au ratio (Fig. 9a).

\subsection{Coupling to other schemes}

We can also examine the effect of coupling of the microphysics to other cloud schemes in the model. The CLUBB simulation uses a different unified higher-order closure scheme to replace the CAM large-scale condensation, shallow convection and boundary layer scheme, as described by Bogenschutz et al. (2013). It uses MG2 with a different substepping strategy of $5 \mathrm{~min}$ time steps, called six times per model time step.

Notably, CLUBB provides a unified condensation scheme for the boundary layer, stratiform and shallow convection regimes, so that ACI are included in shallow cumulus regimes in this formulation. This results in a substantial increase in ACI from -0.98 to $-1.56 \mathrm{Wm}^{-2}$ (just over $50 \%$ ). The change in LWP ( $\triangle \mathrm{LWP})$ is moderate (Fig. 6b), and less than would be expected based on the ACI (Fig. 7a). CLUBB has a lower change in cloud-top drop number (Figs. 6c and $7 \mathrm{~b}$ ), but a large increase in cloud coverage (Fig. 7d), which likely is contributing to ACI. The increase appears to be occurring in the sub-tropics of the Northern and Southern hemispheres (Fig. 6a) mostly from 20 to $40^{\circ} \mathrm{N}$ over the Pacific and Atlantic (not shown). The increase in ACI over the sub-tropical North Pacific and Atlantic is consistent with ACI being added in shallow cumulus regimes. Further future 

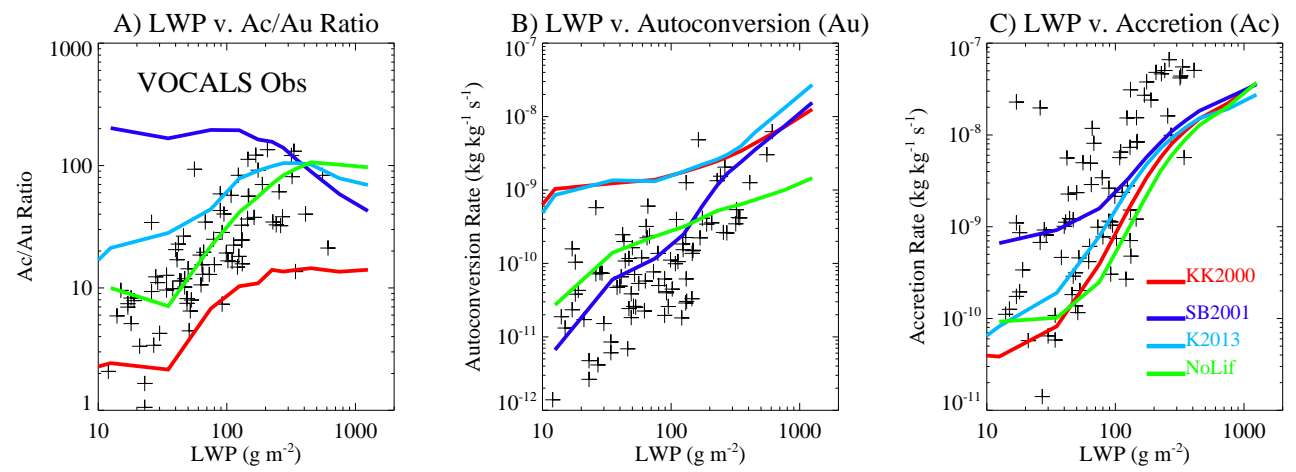

Figure 9. $60^{\circ} \mathrm{S}$ to $60^{\circ} \mathrm{N}$ latitude (a) ratio of accretion to autoconversion, (b) autoconversion rate and (c) accretion rate using KK2000 (red), SB2001 (dark blue), K2013 (cyan) autoconversion and the no lifetime (NoLif) simulation (green). Estimates derived from observations from the VOCALS experiment shown as black crosses (see text for details).

exploration of the impacts of this change is warranted but is beyond the scope of this work. Also notable is that CLUBB simulations have a decrease in the positive LW ACI. This occurs in the tropics, and may be related to changes in transport of water vapor into the upper troposphere, reducing high cloudiness and any positive ACI associated with high (cirrus) clouds. These changes may also be due to differences in how CLUBB treats aerosols and aerosol scavenging in these simulations: it appears that the change in aerosol optical depth (AOD) is larger in CLUBB than in other simulations, perhaps due to different treatment of aerosol scavenging and transport in CLUBB. Thus, a very different physical parameterization suite with the same microphysical process rates can lead to very different ACI.

\subsection{Background emissions}

Finally, we explore the impact of background emissions on ACI. For these experiments no changes to the model are made. The experiments here all use the MG2 code. The only changes are to the emissions files. First, we just explore what happens with different baselines: a larger period (2000-1750) or a smaller period (1850-1750) than the basic 2000-1850 (MG2). As noted, for 1750 emissions, we remove all human sources from the 1850 emissions. So this is really a no anthropogenic emissions case. Figure 7a illustrates that the 2000-1750, MG2 and 1850-1750 changes are fairly linear, with LWP changing about $1 \%$ per $-0.1 \mathrm{Wm}^{-2}$ change in ACI. The changes are also somewhat linear for changes to cloud-top drop number (Fig. 7b) and effective radius (Fig. 7c). Larger changes occur with higher emissions differences. This is not true for cloud coverage changes however (Fig. 7d), where MG2 (2000-1850) and 2000-1750 have about the same decreases in cloud coverage, while there is no change for 1850-1750.

Carslaw et al. (2013) found $\pm 20 \%$ effects on ACI from the assumed level of background emissions. Similar to Carslaw et al. (2013) we conducted experiments by halving (Nat0.5) or doubling (Nat2) the natural emissions of aerosols from dust, volcanoes, ocean dimethylsulfide (DMS) and natural organic carbon (terpenes and other biological aerosols). This was done for both pre-industrial and present emissions. Halving natural emissions makes the model more sensitive to anthropogenic aerosols $\left(-1.13\right.$ to $-1.24 \mathrm{Wm}^{-2} \mathrm{ACI}$ in Table 2, a $27 \%$ increase), whereas doubling emissions decreases the sensitivity significantly ( -0.98 to $-0.68 \mathrm{Wm}^{-2}$ ACI in Table 2, a $30 \%$ decrease). The total change in TOA flux (dR) ranges from $-1.46(+34 \%)$ to $-0.87 \mathrm{Wm}^{-2}(-17 \%)$ in Table 2 . There is little change in LW ACI. Thus we can conclude that the background natural aerosols are important for determining the total ACI.

The variation in natural emissions alters present-day AOD. Global mean AOD for Nat2, baseline (Nat1) and Nat0.5 is $0.175,0.137$ and 0.117 , respectively, with most of the difference caused by the imposed change to the efficiency of dust production and the dust AOD of 0.042, 0.024 and 0.013, respectively, for natural emissions scaling of 2, 1 and 0.5 . This highlights and confirms the need to better constrain background aerosols identified by Carslaw et al. (2013).

\subsection{Summary of sensitivity tests}

The sensitivity of ACI in the global model in terms of the percent change in ACI $(\triangle \mathrm{CRE})$ is illustrated in Fig. 10. Different categories correspond to groups of sensitivity tests noted above. The autoconversion scheme is particularly important, also manifested through lifetime effects (Fig. 3) that change the overall mean LWP in simulations. The SB2001 parameterization that reduces autoconversion at low LWP reduces ACI, and also reproduces estimates of autoconversion rates better (Fig. 9). Different autoconversion parameterizations can change ACI by $35 \%$, and lifetime effects in CESM account for about one-third of total ACI. The use of prognostic precipitation, and the evaporation of rain also affect ACI, largely through a similar mechanism of changing the balance 


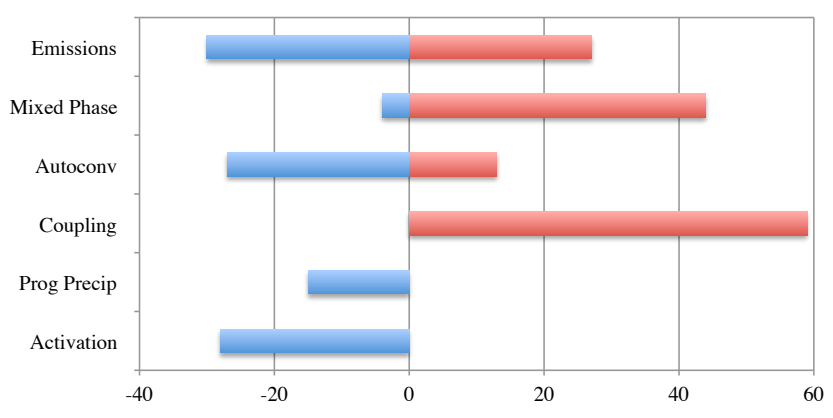

Figure 10. Percent change in ACI for different dimensions of sensitivity tests as described in the text.

between accretion and autoconversion: with more accretion using prognostic rain.

Changes to the mixed phase of clouds, in particular a reduction of the rate of vapor deposition (Berg0.1) to account for sub-grid inhomogeneity, result in an increase in the sensitivity of ACI to LWP. Reducing vapor deposition in the mixed phase increases the occurrence of liquid over ice. Liquid has a longer lifetime (and hence larger average shortwave radiative effect), and liquid clouds are more readily affected by sulfate aerosols than ice clouds are (only homogeneous freezing is affected by sulfate). The change to mixed phase ice nucleation (Hoose) has little impact on the net ACI, but a big impact on the LW. LW and SW effects for colder clouds tend to nearly cancel, with a slightly positive residual (similar to the net cloud forcing for cold clouds), so the LW does not have a strong effect typically on the net ACI in the sensitivity tests, but it does show that changes to colder clouds that effect the LW may increase the gross magnitude of ACI.

Coupling of the microphysics to different turbulence closures and adding the treatment of $\mathrm{ACI}$ in shallow convection (CLUBB) alters ACI by over $50 \%$ (Fig. 10). ACI in deep convection are still not treated, and this may also be important for ACI (Lohmann et al., 2008).

Changing activation to allow all processes to see revised number concentrations lowers ACI by $25 \%$ (MG1 vs. MG1.5), likely due to buffering of the change to activation by other processes in the microphysics.

These microphysical effects are larger than aerosol processes or emissions uncertainties (the "A" in ACI). Natural (or background) emissions can alter the ACI significantly with the same cloud microphysics code, seen in the emissions bar in Fig. 10, with variability from -30 to $+30 \%$, consistent with previous work (Carslaw et al., 2013), indicating $\pm 20 \%$ sensitivity of ACI to similar perturbations of natural emissions. Carslaw et al. (2013) also noted ACI sensitivity of $\pm 10 \%$ to aerosol processes, much smaller than the sensitivity to microphysical processes noted here.

\section{Discussion/conclusions}

Results of idealized and global model tests of a cloud microphysics scheme indicate strong sensitivity of ACI, the radiative response of clouds to aerosol perturbations, to cloud microphysics. Idealized experiments illustrate the different dimensions of aerosol-cloud interactions, and how different cloud regimes may be affected in different ways by idealized aerosol perturbations. The idealized tests show that the representation of the autoconversion process is critical for cloud microphysical response to different drop numbers. These tests are consistent with and help motivate global sensitivity tests.

The sensitivity of ACI to the cloud microphysics with MG2 is -30 to $+55 \%$, larger than the effects of background emissions $(-30$ to $+30 \%)$. Better representations of cloud microphysical processes (the " $\mathrm{C}$ " in ACI) are critical for representing the total forcing from changes in aerosols. These effects are stronger than uncertainties in aerosol emissions or processes. These sensitivity tests are not exhaustive in any statistical sense but form a baseline based on expert judgement, including processes identified by previous work that have been found to be important. We also note that the relative importance between these dimensions of microphysics and aerosols is important. A more significant perturbed parameter ensemble, similar in spirit to Carslaw et al. (2013) but including cloud microphysical uncertainties, is currently being developed.

Uncertain lifetime effects are manifest in CESM through changes to LWP with changes in aerosols. Lifetime effects in CESM represent about one-third of the total ACI. The mixed phase and the shallow convective regimes are also important, indicating that aerosol effects in convective clouds should be considered. Autoconversion parameterizations in particular seem to specify lifetime effects that are highly uncertain. Many global models still prescribe cloud drop number or size based on aerosol mass. This may be problematic as interactions with different microphysical processes are important for the magnitude of ACI.

How general are these results across models? The model framework with MG2 is a typical two-moment bulk microphysics scheme with a framework similar to other schemes. Many of the process rate formulations for autoconversion examined here (e.g., KK2000) are used by other schemes as well. The sensitivity to background aerosol emissions is very similar to that diagnosed by Carslaw et al. (2013). In addition, the sensitivity of the microphysical process rates to autoconversion and accretion that occurs with prognostic precipitation is qualitatively similar to Posselt and Lohmann (2008). However, adding aerosol effects in all convective clouds (deep and shallow) in a different GCM reduced the ACI (Lohmann et al., 2008).

Similar tests with different microphysics schemes, and using different GCMs, would be valuable to confirm the conclusion that ACI sensitivity to cloud processes is large. We 
are in the process of developing such a cross-model comparison. The overall conclusion is that getting better a representation of ACI is critical for reducing uncertainty in anthropogenic climate forcing: cloud microphysical development needs to go hand in hand with better constraints on aerosol emissions to properly constrain ACI and total forcing.

Acknowledgements. Thanks to A. Seifert for comments, discussion and inspiration and to C.-C. Chen for discussions. Computing resources were provided by the Climate Simulation Laboratory at National Center for Atmospheric Research (NCAR) Computational and Information Systems Laboratory. NCAR is sponsored by the U.S. National Science Foundation (NSF). This work was partially conducted on a visit with support of the Max Planck Institute for Meteorology, Hamburg, Germany.

Edited by: C. Hoose

\section{References}

Abdul-Razzak, H. and Ghan, S. J.: A parameterization of aerosol activation 2. Multiple aerosol types, J. Geophys. Res., 105, 68376844, 2000.

Abdul-Razzak, H. and Ghan, S. J.: A parameterization of aerosol activation 3. Sectional Representation, J. Geophys. Res., 107, AAC 1-1-AAC 1-2, doi:10.1029/2001JD000483, 2002.

Albrecht, B. A.: Aerosols, cloud microphysics and fractional cloudiness, Science, 245, 1227-1230, 1989.

Bogenschutz, P. A., Gettelman, A., Morrison, H., Larson, V. E., Craig, C., and Schanen, D. P.: Higher-order turbulence closure and its impact on Climate Simulation in the Community Atmosphere Model, J. Climate., 26, 9655-9676, doi:10.1175/JCLI-D13-00075.1, 2013.

Boucher, O., Randall, D., Artaxo, P., Bretherton, C., Feingold, G., Forster, P., Kerminen, V.-M., Kondo, Y., Liao, H., Lohmann, U., Rasch, P., Satheesh, S. K., Sherwood, S., Stevens, B., and Zhang, X. Y.: Clouds and Aerosols, in: Climate Change 2013: The Physical Science Basis. Contribution of Working Group I to the Fifth Assessment Report of the Intergovernmental Panel on Climate Change, edited by: Stocker, T. F., Qin, D., Plattner, G.-K., Tignor, M., Allen, S. K., Boschung, J., Nauels, A., Xia, Y., Bex, V., and Midgley, P. M., Cambridge Universtiy Press, 2013.

Carslaw, K., Lee, L., Reddington, C., Pringle, K., Rap, A., Forster, P., Mann, G., Spracklen, D., Woodhouse, M., Regayre, L., and others: Large contribution of natural aerosols to uncertainty in indirect forcing, Nature, 503, 67-71, doi:10.1038/nature12674, 2013.

Gettelman, A. and Morrison, H.: Advanced Two-Moment Bulk Microphysics for Global Models. Part I: Off-Line Tests and Comparison with Other Schemes, J. Climate, 28, 1268-1287, doi:10.1175/JCLI-D-14-00102.1, 2015.

Gettelman, A., Liu, X., Barahona, D., Lohmann, U., and Chen, C. C.: Climate Impacts of Ice Nucleation, J. Geophys. Res., 117, D20201, doi:10.1029/2012JD017950, 2012.

Gettelman, A., Morrison, H., Terai, C. R., and Wood, R.: Microphysical process rates and global aerosol-cloud interactions, At- mos. Chem. Phys., 13, 9855-9867, doi:10.5194/acp-13-98552013, 2013.

Gettelman, A., Morrison, H., Santos, S., Bogenschutz, P., and Caldwell, P. M.: Advanced Two-Moment Bulk Microphysics for Global Models. Part II: Global Model Solutions and Aerosol-Cloud Interactions, J. Climate, 28, 1288-1307, doi:10.1175/JCLI-D-14-00103.1, 2015.

Ghan, S. J.: Technical Note: Estimating aerosol effects on cloud radiative forcing, Atmos. Chem. Phys., 13, 9971-9974, doi:10.5194/acp-13-9971-2013, 2013.

Ghan, S. J., Smith, S. J., Wang, M., Zhang, K., Pringle, K., Carslaw, K., Pierce, J., Bauer, S., and Adams, P.: A simple model of global aerosol indirect effects, J. Geophys. Res.-Atmos., 118, 66886707, doi:10.1002/jgrd.50567, 2013.

Guo, H., Golaz, J.-C., and Donner, L. J.: Aerosol effects on stratocumulus water paths in a PDF-based parameterization, Geophys Res. Lett., 38, L17808, doi:10.1029/2011GL048611, 2011.

Hoose, C., Kristjansson, J. E., Chen, J. P., and Hazra, A.: A classical-theory-based parameterization of heterogeneous ice nucleation by mineral dust, soot and biological particles in a global climate model, J. Atmos. Sci., 67, 2483-2503, doi:10.1175/2010JAS3425.1, 2010.

Jiang, H., Feingold, G., and Sorooshian, A.: Effect of Aerosol on the Susceptibility and Efficiency of Precipitation in Warm Trade Cumulus Clouds, J. Atmos. Sci., 67, 3526-3540, 2010.

Khairoutdinov, M. F. and Kogan, Y.: A new cloud physics parameterization in a large-eddy simulation model of marine stratocumulus, Mon. Weather Rev., 128, 229-243, 2000.

Kiehl, J. T., Schneider, T. L., Rasch, P. J., and Barth, M. C.: Radiative forcing due to sulfate aerosols from simulations with the National Center for Atmospheric Research Community Climate Model, version 3, J. Geophys. Res., 105, 1441-1457, 2000.

Kogan, Y.: A Cumulus Cloud Microphysics Parameterization for Cloud-Resolving Models, J. Atmos. Sci., 70, 1423-1436, doi:10.1175/JAS-D-12-0183.1, 2013.

Korolev, A.: Limitations of the Wegener-Bergeron-Findeisen Mechanism in the Evolution of Mixed-Phase Clouds, J. Atmos. Sci., 64, 3372-3375, doi:10.1175/JAS4035.1, 2007.

Korolev, A. V.: Rates of phase transformations in mixedphase clouds, Q. J. Roy. Meteorol. Soc., 134, 595-608, doi:10.1002/qj.230, 2008.

Lawson, R. P. and Gettelman, A.: Impact of Antarctic mixed-phase clouds on climate, P. Natl. Acad. Sci. USA, 111, 18156-18161, doi:10.1073/pnas.1418197111, 2014.

Liu, X., Penner, J. E., and Wang, M.: Inclusion of ice microphysics in the NCAR Community Atmosphere Model version 3 (CAM3), J. Climate, 20, 4526-4547, 2007.

Liu, X., Easter, R. C., Ghan, S. J., Zaveri, R., Rasch, P., Shi, X., Lamarque, J.-F., Gettelman, A., Morrison, H., Vitt, F., Conley, A., Park, S., Neale, R., Hannay, C., Ekman, A. M. L., Hess, P., Mahowald, N., Collins, W., Iacono, M. J., Bretherton, C. S., Flanner, M. G., and Mitchell, D.: Toward a minimal representation of aerosols in climate models: description and evaluation in the Community Atmosphere Model CAM5, Geosci. Model Dev., 5, 709-739, doi:10.5194/gmd-5-709-2012, 2012.

Lohmann, U. and Feichter, J.: Global indirect aerosol effects: a review, Atmos. Chem. Phys., 5, 715-737, doi:10.5194/acp-5-7152005, 2005. 
Lohmann, U., Spichtinger, P., Jess, S., Peter, T., and Smit, H.: Cirrus cloud formation and ice supersaturated regions in a global climate model, Environ. Res. Lett., 3, 045022, http://stacks.iop. org/1748-9326/3/045022, 2008.

Menon, S., Genio, A. D. D., Koch, D., and Tselioudis, G.: GCM Simulations of the Aerosol Indirect Effect: Sensitivity to Cloud Parameterization and Aerosol Burden, J. Atmos. Sci., 59, 692-713, doi:10.1175/15200469(2002)059<0692:GSOTAI > 2.0.CO;2, 2002.

Meyers, M. P., DeMott, P. J., and Cotton, W. R.: New Primary Ice-Nucleation Parameterizations in an Explicit Cloud Model, J. Appl. Meteorol., 31, 708-721, 1992.

Morrison, H. and Gettelman, A.: A new two-moment bulk stratiform cloud microphysics scheme in the NCAR Community Atmosphere Model (CAM3), Part I: Description and Numerical Tests, J. Climate, 21, 3642-3659, 2008.

Neale, R. B., Chen, C. C., Gettelman, A., Lauritzen, P. H., Park, S., Williamson, D. L., Conley, A. J., Garcia, R., Kinnison, D., Lamarque, J. F., Marsh, D., Mills, M., Smith, A. K., Tilmes, S., Vitt, F., Cameron-Smith, P., Collins, W. D., Iacono, M. J., Easter, R. C., Ghan, S. J., Liu, X., Rasch, P. J., and Taylor, M. A.: Description of the NCAR Community Atmosphere Model (CAM5.0), Tech. Rep. NCAR/TN-486+STR, National Center for Atmospheric Research, Boulder, CO, USA, 2010.

Penner, J. E., Quaas, J., Storelvmo, T., Takemura, T., Boucher, O., Guo, H., Kirkevåg, A., Kristjánsson, J. E., and Seland, Ø.: Model intercomparison of indirect aerosol effects, Atmos. Chem. Phys., 6, 3391-3405, doi:10.5194/acp-6-3391-2006, 2006.

Pincus, R. and Baker, M. B.: Effect of precipitation on the albedo susceptibility of clouds in the marine boundary layer, Nature, 372, 250-252, 1994.

Posselt, R. and Lohmann, U.: Introduction of prognostic rain in ECHAM5: design and single column model simulations, Atmos. Chem. Phys., 8, 2949-2963, doi:10.5194/acp-8-2949-2008, 2008.

Rosenfeld, D., Lohmann, U., Raga, G. B., O’Dowd, C. D., Kulmala, M., Fuzzi, S., Reissell, A., and Andreae, M. O.: Flood or Drought: How do Aerosols Affect Precipitation, Science, 321, 1309-1313, 2008.

Rotstayn, L. D. and Liu, Y.: A smaller global estimate of the second indirect aerosol effect, Geophys. Res. Lett., 32, L05708, doi:10.1029/2004GL021922, 2005.
Seifert, A. and Beheng, K. D.: A double-moment parameterization for simulating autoconversion, accretion and selfcollection, Atmos. Res., 59-60, 265-281, 2001.

Shipway, B. J. and Hill, A. A.: Diagnosis of systematic differences between multiple parametrizations of warm rain microphysics using a kinematic framework, Q. J. Roy. Meteorol. Soc., 138, 2196-2211, doi:10.1002/qj.1913, 2012.

Stevens, B. and Feingold, G.: Untangling aerosol effects on clouds and precipitation in a buffered system, Nature, 461, 607-613, 2009.

Terai, C. R., Wood, R., Leon, D. C., and Zuidema, P.: Does precipitation susceptibility vary with increasing cloud thickness in marine stratocumulus?, Atmos. Chem. Phys., 12, 4567-4583, doi:10.5194/acp-12-4567-2012, 2012.

Twomey, S.: The influence of pollution on the shortwave albedo of clouds, J. Atmos. Sci., 34, 1149-1152, 1977.

Twomey, S. and Squires, P.: The Influence of Cloud Nucleus Population on the Microstructure and Stability of Convective Clouds, Tellus, 9, 408-411, 1959.

Wang, M., Ghan, S., Liu, X., L’Ecuyer, T. S., Zhang, K., Morrison, H., M. Ovchinnikov, R. E., Marchand, R., Chand, D., Qian, Y., and Penner, J. E.: Constraining cloud lifetime effects of aerosols using A-Train Satellite observations, Geophys. Res. Lett., 39, L15709, doi:10.1029/2012GL052204, 2012.

Wood, R., Kubar, T. L., and Hartmann, D. L.: Understanding the Importantce of Microphysics and Macrophysics for Warm Rain in Marine Low Clouds. Part II: Heuristic Models of Rain Formation, J. Atmos. Sci., 66, 2973-2990, doi:10.1175/2009JAS3072.1, 2009.

Zhang, Y., Stevens, B., and Ghil, M.: On the diurnal cycle and susceptibility to aerosol concentration in a stratocumulustopped mixed layer, Q. J. Roy. Meteorol. Soc., 131, 1567-1583, doi:10.1256/qj.04.103, 2005.

Zhao, C., Liu, X., Qian, Y., Yoon, J., Hou, Z., Lin, G., McFarlane, S., Wang, H., Yang, B., Ma, P.-L., Yan, H., and Bao, J.: A sensitivity study of radiative fluxes at the top of atmosphere to cloudmicrophysics and aerosol parameters in the community atmosphere model CAM5, Atmos. Chem. Phys., 13, 10969-10987, doi:10.5194/acp-13-10969-2013, 2013. 